\section{Molecular analysis of representative Streptococcus gordonii Spp phase variants reveals no differences in the glucosyltransferase structural gene, gtfG}

Vickerman MM, Jones GW, Clewell DB. Molecular analysis of representative Streptococcus gordonii Spp phase variants reveals no differences in the glucosyltransferase structural gene, gtfG.

Oral Microbiol Immunol 1997: 12: 82-90. (c) Munksgaard, 1997.

Streptococcus gordonii glucosyltransferase polymerizes sucrose to form glucans, which confer a hard, sucrose-promoted phenotype $\left(\mathrm{Spp}^{+}\right)$to colonies on sucrose agar plates. The glucosyltransferase structural gene, $g t f G$, is positively regulated by the upstream determinant, rgg. Strain Challis undergoes a spontaneous, reversible phase variation between high $\left(\mathrm{Spp}^{+}\right)$and low ( $\left.\mathrm{Spp}^{-}\right)$levels of glucosyltransferase activity. Representative strains were examined to gain insights into the basis of glucosyltransferase phase variation. Western blots indicated that the level of glucosyltransferase activity was related to the amount of extracellular glucosyltransferase protein produced by $\mathrm{Spp}^{-}$and $\mathrm{Spp}^{+}$strains. The nucleotide sequence of $r g g$ and $g t f G$ of the $\mathrm{Spp}^{-}$strain $\mathrm{CH} 97$ was found to be identical to that of the $\mathrm{Spp}^{+}$parent, indicating that DNA differences in these regions are not the basis for glucosyltransferase phase variation. Indeed, ${ }^{13} \mathrm{C}$-NMR spectroscopy suggested that glucans synthesized by strain $\mathrm{CH} 97$ glucosyltransferase were similar to those synthesized by glucosyltransferase of the $\mathrm{Spp}^{+}$parental strain, indicating a quantitative rather than qualitative change. However, one $\mathrm{Spp}^{-}$strain, $\mathrm{CH} 1 \mathrm{Cl}$, had a point mutation in $\mathrm{rgg}$; replacement of the parent $\mathrm{rgg}$ with the $\mathrm{CH} 1 \mathrm{C} 1$ allele resulted in decreased levels of glucosyltransferase protein and activity. The results indicate that glucosyltransferase phase variation can occur in more than one way, and suggest that glucosyltransferase regulation may involve distally located regulatory gene(s) that affect $r g g$ and/or $g t f G$ expression.

\section{M. Vickerman ${ }^{1}$, G. W. Jones ${ }^{1}$, D. B. Clewell ${ }^{1,2}$}

${ }^{1}$ Department of Microbiology and Immunology, School of Medicine, ${ }^{2}$ Department of Biologic and Materials Sciences, School of Dentistry, University of Michigan, Ann Arbor, USA
Key words: Streptococcus gordonii; oral streptococci; glucosyltransferase; phase variation; nucleotide sequence

M. M. Vickerman, Department of Microbiology and Immunology, 5641 Medical Science II Building, University of Michigan School of Medicine, Ann Arbor, MI 48109-0620, USA

Accepted for publication July 18, 1996
Streptococcus gordonii is a significant component of early, supragingival dental plaque (5) and a potential pathogen associated with infective endocarditis $(18,22)$. These bacteria have a single extracellular glucosyltransferase enzyme that polymerizes sucrose to make glucans with varying proportions of $\alpha 1,6$ and $\alpha 1,3$ linkages resulting in wa- ter-soluble and water-insoluble polymers $(8,10)$. Although the glucosyltransferase enzymes of the mutans streptococci have been extensively studied due to their potential role as virulence factors (14), little is known about the functions of glucosyltransferases of other oral streptococci.

S. gordonii strain Challis $\mathrm{CH} 1$ under- goes a spontaneous, reversible phase variation between high $\left(\mathrm{Spp}^{+}\right)$and low $\left(\mathrm{Spp}^{-}\right)$levels of glucosyltransferase activity (28). Phase variation is thought to provide bacteria with ecologically advantageous alternatives (20), which could be particularly important in the rapid, extreme changes of the oral environment. Although the in vivo role of 
Table 1. Bacterial strains and plasmids used in these studies

\begin{tabular}{|c|c|c|}
\hline & Relevant characteristics & $\begin{array}{l}\text { Source or } \\
\text { reference }\end{array}$ \\
\hline \multicolumn{3}{|l|}{ Bacteria } \\
\hline \multicolumn{3}{|l|}{ S. gordonii } \\
\hline $\mathrm{CH} 1$ & parental Challis strain, $\mathrm{Spp}^{+}$ & 28 \\
\hline $\mathrm{CH} 1 \mathrm{~A} 8$ & $\mathrm{Spp}^{-}$phase variant of strain $\mathrm{CH} 1$ & 28 \\
\hline CH1B1 & $\mathrm{Spp}^{+}$phase variant of strain $\mathrm{CH} 1 \mathrm{~A} 8$ & 28 \\
\hline $\mathrm{CH} 1 \mathrm{C} 1$ & $\mathrm{Spp}^{-}$phase variant of strain $\mathrm{CH} 1 \mathrm{~B} 1$ & 28 \\
\hline $\mathrm{CH} 1 \mathrm{D} 2$ & $\mathrm{Spp}^{+}$phase variant of strain $\mathrm{CH} 1 \mathrm{Cl}$ & 28 \\
\hline $\mathrm{CH} 97$ & $\mathrm{Spp}^{-}$phase variant of strain $\mathrm{CH} 1$ & 28 \\
\hline $\mathrm{CHC} 10 \mathrm{E}$ & $\begin{array}{l}\text { CH1 with chromosomally integrated pAM6203; } \\
\mathrm{erm}^{\mathrm{r}}\end{array}$ & This study \\
\hline $\mathrm{CHC} 102$ & $\mathrm{erm}^{\mathrm{s}}, \mathrm{Spp}^{-}$derivative of $\mathrm{CHC} 10 \mathrm{E}$ & This study \\
\hline $\mathrm{CHC} 105$ & $\mathrm{erm}^{\mathrm{s}}, \mathrm{Spp}^{-}$derivative of $\mathrm{CHC1OE}$ & This study \\
\hline $\mathrm{CHC} 10 \mathrm{H}$ & $\mathrm{erm}^{\mathrm{s}}, \mathrm{Spp}^{+}$derivative of $\mathrm{CHC} 10 \mathrm{E}$ & This study \\
\hline \multicolumn{3}{|c|}{ 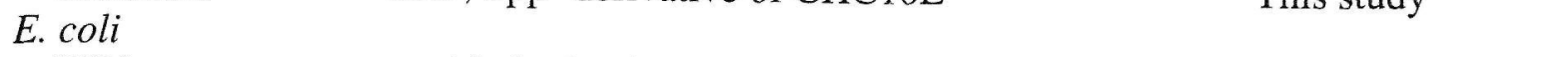 } \\
\hline $\mathrm{DH} 5 \alpha$ & recAl cloning host strain & $\begin{array}{l}\text { Bethesda Research } \\
\text { Laboratories }\end{array}$ \\
\hline \multicolumn{3}{|l|}{ Plasmids } \\
\hline pVA891 & $\begin{array}{l}\text { E. coli vector, no gram-positive replication origin; } \\
\mathrm{em}^{\mathrm{r}}\end{array}$ & 15 \\
\hline pBluescript $\mathrm{KSII}^{+}$ & E. coli vector; $\mathrm{Ap}^{\mathrm{r}}$ & $\begin{array}{l}\text { Stratagene Cloning } \\
\text { Systems }\end{array}$ \\
\hline pAM6203 & $\begin{array}{l}\text { ca. 1.2-kb fragment carrying rgg of strain } \\
\text { CH1C1 in pVA891 }\end{array}$ & This study \\
\hline
\end{tabular}

glucosyltransferase phase variation is unknown, in vitro studies with $S$. gordonii $\mathrm{Spp}^{+}$and $\mathrm{Spp}^{-}$strains suggest that these cells have different abilities to attach to and accumulate on various surfaces under different environmental conditions (30-32) and provide intriguing preliminary evidence that glucosyltransferase phase variation may allow differential colonization of oral sites. Additional phenotypic changes in cell surface properties that potentially could affect colonization, such as the ability of the cells to coaggregate or produce hemolysin, also undergo reversible phase variation in $S$. gordonii (11). Phase variation in one phenotype correlates with an increased probability of phase variation in additional phenotype(s) (11). The relationship between glucosyltransferase phase variation and variation in these other $S$. gordonii cellular phenotypes is unknown, and more than one mechanism may be involved.

The strain Challis glucosyltransferase structural gene, $g t f G$, is similar to other streptococcal $g t f$ genes (35). After a conserved signal sequence, there is an approximately 600-bp region distinct for $S$. gordonii gtfG, followed by a conserved region encoding a putative catalytic site $(6,17)$. In the region encoding the carboxyl terminus there is a series of six direct repeats thought to be involved in glucan binding $(4,16)$. The open reading frame is followed by a region of dyad symmetry that may function in transcriptional termination (35). gtfG is positively regulated by the upstream gene, $r g g$ (27); rgg is the only described regulatory determinant for a streptococcal gtf gene and is able to act in trans to increase glucosyltransferase activity in both $\mathrm{Spp}^{+}$and $\mathrm{Spp}^{-}$strains (27). Southern hybridization analyses indicate that rgg- and $g t f G$-like determinants are present in other early plaque organisms including other $S$. gordonii strains as well as Streptococcus sanguis and Streptococcus oralis (34).

No major DNA rearrangements in rgg/gtfG and their flanking regions have been detected in phase variant strains (27). The level of glucosyltransferase activity varies among different $\mathrm{Spp}^{+}$and $\mathrm{Spp}^{-}$strains (28), suggesting that phase variation is not due to an "on-off" switch. The purpose of the present studies was to further characterize representative phase variant strains and to examine the genes known to be involved in glucosyltransferase expression in these strains in an attempt to better understand the basis for glucosyltransferase phase variation at the DNA level.

\section{Material and methods Bacterial strains and plasmids}

S. gordonii $\mathrm{CH} 1$ (28) was the parental strain Challis. A series of glucosyltransferase phase variants (28) that were sequentially derived from the $\mathrm{Spp}^{+}$parent strain $\mathrm{CH} 1$ [strain $\mathrm{CH} 1 \mathrm{~A} 8$ (Sppvariant of strain $\mathrm{CH} 1), \mathrm{CH} 1 \mathrm{~B} 1 \mathrm{Spp}^{+}$ revertant of strain $\mathrm{CH} 1 \mathrm{~A} 8), \mathrm{CH} 1 \mathrm{C} 1$ $\left(\mathrm{Spp}^{-}\right.$variant of strain $\left.\mathrm{CH} 1 \mathrm{~B} 1\right)$ and $\mathrm{CH} 1 \mathrm{D} 2 \mathrm{(Spp}^{+}$revertant of strain $\mathrm{CH} 1 \mathrm{C} 1)]$ as well as the independently derived, reversible $\mathrm{Spp}^{-}$variant $\mathrm{CH} 97$ were the phase variant strains chosen for examination. The relevant characteristics and references for bacterial strains and plasmids used in this study are listed in Table 1.

\section{Media and growth conditions}

S. gordonii strains were grown in Todd Hewitt medium (Difco Laboratories, Detroit, $\mathrm{MI}$ ) at $37^{\circ} \mathrm{C}$ in a candle jar or anaerobically (Gas Pak Plus Anaerobic System, BBL Microbiology Systems, Cockeysville, MD). Strains with integrated pVA891 (15) or pAM6203 were grown with $5 \mu \mathrm{g} / \mathrm{ml}$ erythromycin. Spp colony morphology was determined as hard $\left(\mathrm{Spp}^{+}\right)$or soft $\left(\mathrm{Spp}^{-}\right)$on Todd Hewitt $3 \%$ sucrose agar plates (28). For in vitro glucan synthesis and analysis, cells were grown in defined FMC medium (29) in an anaerobic chamber (Coy Industries, Jackson, MI).

Escherichia coli DH5 $\alpha$ strains with cloned inserts in pBluescript were selected on LB (2) agar plates containing $100 \mu \mathrm{g} / \mathrm{ml}$ ampicillin, $0.5 \mathrm{mM}$ isopropyl- $\beta$ - $D$-thiogalactopyranoside and 12 $\mathrm{mM}$ 5-bromo-4-chloro-3-indolyl- $\beta$-Dgalactopyranoside. E. coli DH5a strains containing recombinant $\mathrm{pBluescript}$ plasmids were grown in LB medium with $100 \mu \mathrm{g} / \mathrm{ml}$ ampicillin. DH5 $\alpha$ strains carrying pVA891 or pAM6203 were grown in $200 \mu \mathrm{g} / \mathrm{ml}$ erythromycin.

\section{DNA isolation and manipulation}

Streptococcal chromosomal DNA was prepared by a modified Sarkosyl lysis procedure using mutanolysin and lysozyme (34). Double-stranded DNA subclones or polymerase chain reaction fragments were digested with appropriate restriction enzymes, ligated with T4 DNA ligase into the multiple cloning region of pBluescript $\mathrm{KSII}^{+}$, and transformed into $E$. coli $\mathrm{DH} 5 \alpha$ by the $\mathrm{CaCl}_{2}$ method (2). Plasmid DNA from $E$. coli was prepared by Qiagen purification columns (Qiagen, Chatsworth, CA) according to the manufacturer's directions. $S$. gordonii strains were transformed by a 
MAP

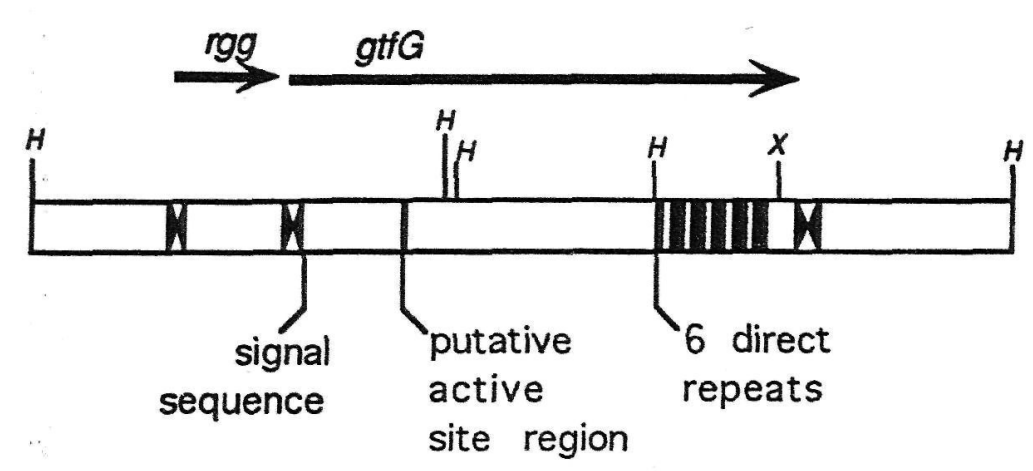

FRAGMENT

PRIMERS USED

5'GGATCCCAGGTGTTTTAGTAT3'
5'AAGCTTATCCGTTGCTTTGTC3'

5'GGATCCAAGAAAATCTGGGAATCG3'

5'GGTCATTCAGACTGTTCGTAATCG3'

5'GGATCCTTCAATGGTACCAATATCTTAGGTCG3' 5'CATCCAAGTTCCGTCTTCTAGAC3'

5'GGATCCAAGGCTATCTAGTGACAG3'

5'AAGCTTGACATTGAGTTAAATGTATTC3'

5'AAGCTTGAATCAGGTGTGATCTAT3'
5'GGTCATTCAGACTGTTCGTAATCG3'

\section{5'GCATCTGACTACTTCAAGTCTCGC3'} 5'AGCTCCTGTCACTAGATAGCCTTG3'

Fig. 1. Polymerase chain reaction-generated subclones used for determining the nucleotide sequence of $\mathrm{Spp}^{+}$and $\mathrm{Spp}^{-} \mathrm{phase}^{\mathrm{sariant}} \mathrm{strains}$. The GenBank accession numbers for the strain CH1 rgg (27) and gtfG (35) sequences are M89776 and U12643, respectively. The map shows the relative position of each fragment. The heavy arrows above the map indicate the $\mathrm{rg} g$ and $g t f G$ open reading frames. Regions of dyad symmetry are indicated by inverted arrows. Relevant regions of $g t f G$ are described. The oligonucleotide primers listed for fragments i, ii, iii, and iv were used in polymerase chain reaction with chromosomal template DNA from the phase variant strains $\mathrm{CH} 1 \mathrm{~A} 8, \mathrm{CH} 1 \mathrm{~B} 1, \mathrm{CH} 1 \mathrm{C} 1, \mathrm{CH} 1 \mathrm{D} 2$, and $\mathrm{CH} 97$. Primers either had an engineered flanking BamHI or HindIII site (underlined) or else included, or were immediately upstream from, a convenient restriction site for cloning the double-stranded polymerase chain reaction product into the Bam $\mathrm{HI}(\mathrm{B}), \operatorname{HindIII}(\mathrm{H})$ or XbaI (X) sites of pBluescript $\mathrm{KSII}^{+}$. In some cases partial, rather than complete, HindIII digestion of the polymerase chain reaction fragments was necessary for cloning. To complete the entire sequencing of $g t f G$ and its flanking regions in an $\mathrm{Spp}^{-}$phase variant strain, fragments $\mathrm{v}$ and vi were generated from strain $\mathrm{CH} 97$ chromosomal DNA.

modified method of Lawson \& Gooder (13) using horse serum (27).

\section{Polymerase chain reaction}

Double-stranded polymerase chain reaction products were obtained with a GeneAmp polymerase chain reaction kit in a 480 DNA thermal cycler (PerkinElmer Cetus, Emeryville, CA) using AmpliTaq enzyme as previously described (35). Custom oligonucleotide primers were synthesized at the DNA Core Facility (University of Michigan, Ann Arbor).

\section{Construction of subclones of $r g g$ and gtfG and their flanking regions from phase-variant strains}

Chromosomal DNA samples from Spp ${ }^{+}$ and $\mathrm{Spp}^{-}$phase variant strains were used as templates in polymerase chain reaction reactions with oligonucleotide primers shown in Fig. 1. Primers were designed to amplify areas of interest in rgg, gtfG and their flanking regions. Primers either had engineered $5^{\prime}$ restriction sites or else were designed to anneal to the template immediately $5^{\prime}$ to a convenient restriction site so that digestion of the amplified fragment would facilitate ligation into the multiple cloning region of $\mathrm{pBluescript} \mathrm{KSII}^{+}$. Each polymerase chain reaction gave only one product. To guard against mistakes due to misincorporation of nucleotides during polymerase chain reaction, three independent products from each strain were sequenced.

\section{Nucleotide sequence determination and analysis}

Double-stranded DNA sequencing was done by a modification (35) of the dideoxy chain termination sequencing method (21) using M13 forward and reverse primers for the $\mathrm{pBluescript}$ cloning vector and custom oligonucleotide primers (University of Michigan DNA Core Facility) as necessary. To determine the sequence of the gtfG carboxyl-terminal direct repeat regions that had approximately 600-bp regions without unique sites for custom primers (35), a cycle sequencing method was used at the University of Michigan DNA Core Facility. Templates were sequenced with a PRISM-Ready Reaction Dye Deoxy Terminator Sequencing kit (Applied Biosystems, Foster, CA) using AmpliTaq enzyme according to the manufacturer's directions. Samples were run in a model 373 DNA Stretch Sequencer with analytical software (Applied Biosystems). Both strands of DNA were sequenced.

Individual DNA sequences were stored in AssemblyLign (International Biotechnologies, New Haven, CT) and compared and analyzed with the IBI 


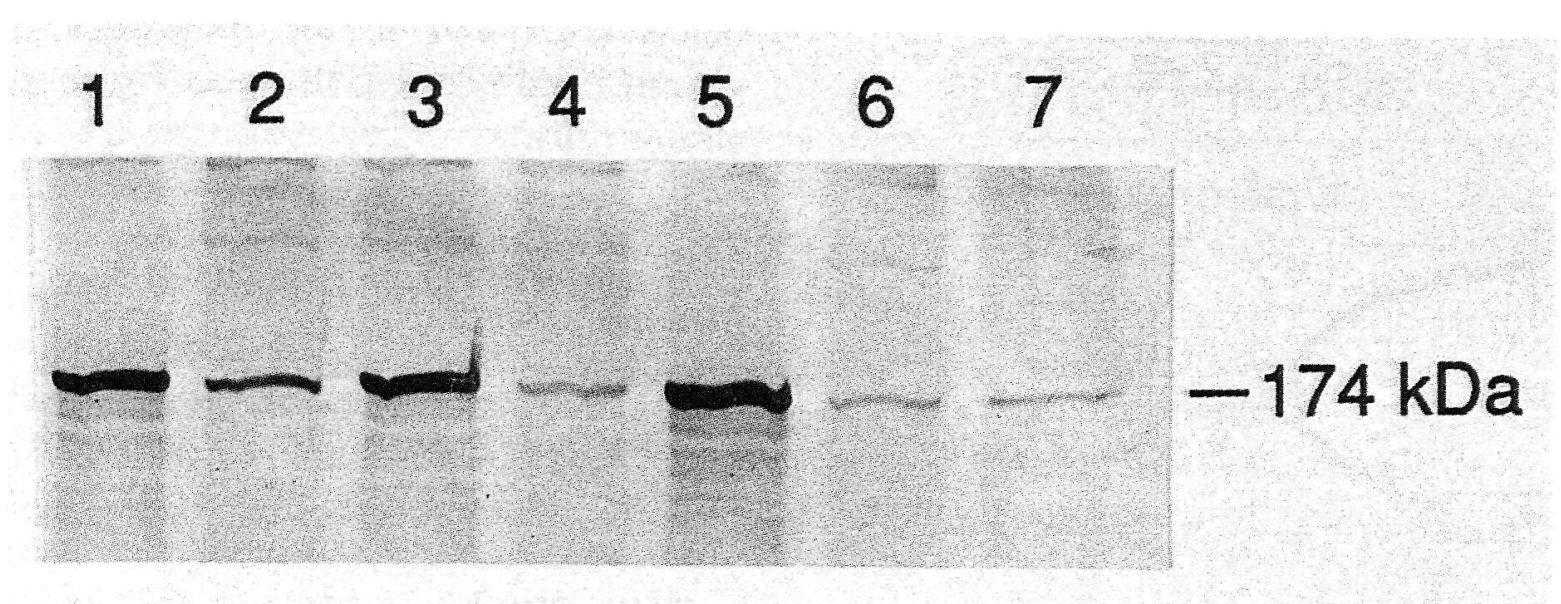

Fig. 2. Western blot analyses of $S$. gordonii strains show that the level of glucosyltransferase activity in each strain is related to the level of extracellular glucosyltransferase antibody-reactive protein. Cultures were grown in $\mathrm{TH}$ broth to the same phase $\left(\mathrm{OD}_{520^{\prime}}=1.2\right)$ and cell-free supernatants were subjected to SDS-PAGE, transferred to polyvinylidene difluoride membranes and GTF-I antibody-reactive proteins were detected. The parental strain CH1 is shown in lane 1. The sequentially derived phase variants are shown in lane 2) the $\mathrm{Spp}^{-}$strain $\mathrm{CH} 1 \mathrm{~A} 8 ; 3$ ) the $\mathrm{Spp}^{+}$strain $\left.\mathrm{CH} 1 \mathrm{~B} 1 ; 4\right)$ the $\mathrm{Spp}^{-}$strain $\left.\mathrm{CH} 1 \mathrm{C} 1 ; 5\right)$ the $\mathrm{Spp}^{+}$strain $\mathrm{CH} 1 \mathrm{D} 2$. The independentlyderived, reversible $\mathrm{Spp}^{-}$strain $\mathrm{CH} 97$ is shown in lane 6. Lane 7 shows strain $\mathrm{CHC102}$ (see text).

MacVector software program (International Biotechnologies).

\section{Determination of glucosyltransferase activity}

For relative comparisons of glucosyltransferase activity, cultures were grown to the same optical density at $520 \mathrm{~nm}$ and the cell-free supernatants were subjected to SDS-PAGE. The relative extracellular glucosyltransferase activity of each strain was determined by densitometric scan of glucosyltransferase activity gels as previously described (27).

\section{Southern hybridization analysis}

DNA was digested with appropriate restriction enzymes, electrophoresed on $0.7 \%$ agarose gels and transferred to Hybond-N (Amersham) membrane based on the method of Southern (2). Probe DNA was labelled with digoxigenin-dUTP, hybridized to the membrane under stringent conditions (2) and detected by chemiluminescence with the Genius System (Boehringer Mannheim, Indianapolis, IN) according to the manufacturer's directions.

\section{Analysis of glucosyltransferase antibody- reactive proteins using Western blots}

S. gordonii strains were grown in Todd Hewitt broth to the same mid-to-late log growth phase (optical density at $520 \mathrm{~nm}$
Chemical Co., St. Louis, MO).

\section{In vitro glucan synthesis}

For glucan analysis, 20-ml cultures of strain $\mathrm{CH} 1$ and strain $\mathrm{CH} 97$ were grown anaerobically in FMC with $1 \mathrm{mM}$ phenylmethylsulfonyl fluoride until late $\log$ phase (optical density at $520 \mathrm{~nm}$ =1.8). Cell-free culture supernatants were concentrated 20-fold in Centricon100 concentrators (100 kDa cutoff; Amicon). This partially purified enzyme was added to $50 \mathrm{ml}$ of filter-sterilized substrate solution consisting of $5 \%$ sucrose, $1 \mathrm{mM}$ phenylmethylsulfonyl fluoride in $0.05 \mathrm{M}$ sodium phosphate buffer, $\mathrm{pH}$ 6.8. After gentle rotation at $37^{\circ} \mathrm{C}$ for $60 \mathrm{~h}$, the glucans were precipitated with 3 volumes of $95 \%$ ethanol at $-20^{\circ} \mathrm{C}$ and collected by centrifugation at $16,000 \times g$. The glucans were washed with water and reprecipitated three times. The final washed glucan products were dried in a Speedvac concentrator (Savant Instruments, Farmingdale, NY). trifugation at $1000 \times g$, supernatants were concentrated 10-fold in Centricon-50 concentrators (50 kDa cutoff; Amicon, Beverly, MA) and equal volumes loaded on $7.5 \%$ SDS-acrylamide gels (12). After electrophoresis, proteins were transferred with a transblot cell (BioRad Laboratories, Hercules, CA) onto polyvinylidene difluoride membranes (Millipore Corporation, Bedford, MA) in $10 \mathrm{mM}$ 3-cyclohexylamino-1-propane sulfonic acid buffer, $\mathrm{pH}$ 11.0. Proteins were detected with polyclonal anti GTF-I rabbit antiserum raised against the product of $S$. mutans GS5 gtfB (26) (a gift from H. K. Kuramitsu). Based on amino acid sequences deduced from the nucleotide sequences $(26,35)$, the GTFI protein is $51.5 \%$ identical to $S$. gordonii $\mathrm{CH} 1$ glucosyltransferase as determined by the GCG Wisconsin Gap program for protein similarity (9). The anti-GTF-I antiserum was sufficiently cross-reactive to detect the $S$. gordonii glucosyltransferase; control blots using increasing amounts of partially purified strain $\mathrm{CH} 1$ glucosyltransferase confirmed that the intensity of the bands on the Western blots was proportional to the amount of $S$. gordonii supernatant extract present. Primary antibody binding was detected with goat anti-rabbit immunoglobulin $G$ alkaline phosphatase conjugate (Bethesda Research Laboratories, Gaithersburg, MD) and 5bromo-4-chloro-3-indolyl phosphate/ nitro blue tetrazolium substrate (Sigma

\section{Nuclear magnetic resonance analysis of glucans}

Glucans synthesized in vitro were examined by ${ }^{13} \mathrm{C}$-NMR spectroscopy at the University of Michigan Core Facility. Spectra of saturated glucans in dimethyl-d6-sulfoxide were obtained in a GE Omega 500 spectrometer at 124 $\mathrm{MHz}$ in a $10-\mathrm{mm}$ tube with a probe temperature of $75^{\circ} \mathrm{C}$. 16,000 data points over a spectral width of $26,315 \mathrm{~Hz}$ for 60,000 scans were collected. Relaxation time was $2.0 \mathrm{~s}$ and digital resolution was $3.2 \mathrm{~Hz}$. Dimethyl-d6-sulfoxide was used as the internal reference (40 ppm). Peak assignments for carbons of glucose moieties in $\alpha 1,6$ and $\alpha 1,3$ linkages were based on data of Colson et al. (3) and Seymour et al. (23).

\section{Adhesion to hydroxyapatite}

The adhesion of cells to hydroxyapatite and saliva-coated hydroxyapatite beads was performed as described previously (32). Briefly, cells were grown anaerobically to late-log phase in the presence of $2 \mu \mathrm{Ci} / \mathrm{ml}$ of $\left[{ }^{3} \mathrm{H}\right]$-thymidine, washed and resuspended to a concentration of approximately $1 \times 10^{8}$ cells $/ \mathrm{ml}$ in buffered $\mathrm{KCl}(1)$. One-ml volumes of radiolabelled cells were incubated for $3.5 \mathrm{~h}$ at $10 \mathrm{rpm}$ with $10 \mathrm{mg}$ of hydroxyapatite beads (BDH, Poole, UK) that had either 


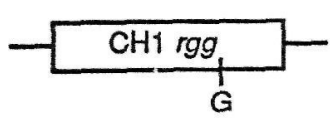

$\mathrm{CH} 1$ parent allele

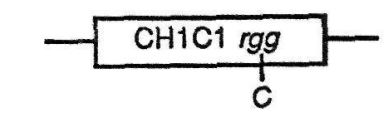

$\mathrm{CH} 1 \mathrm{C} 1$ allele
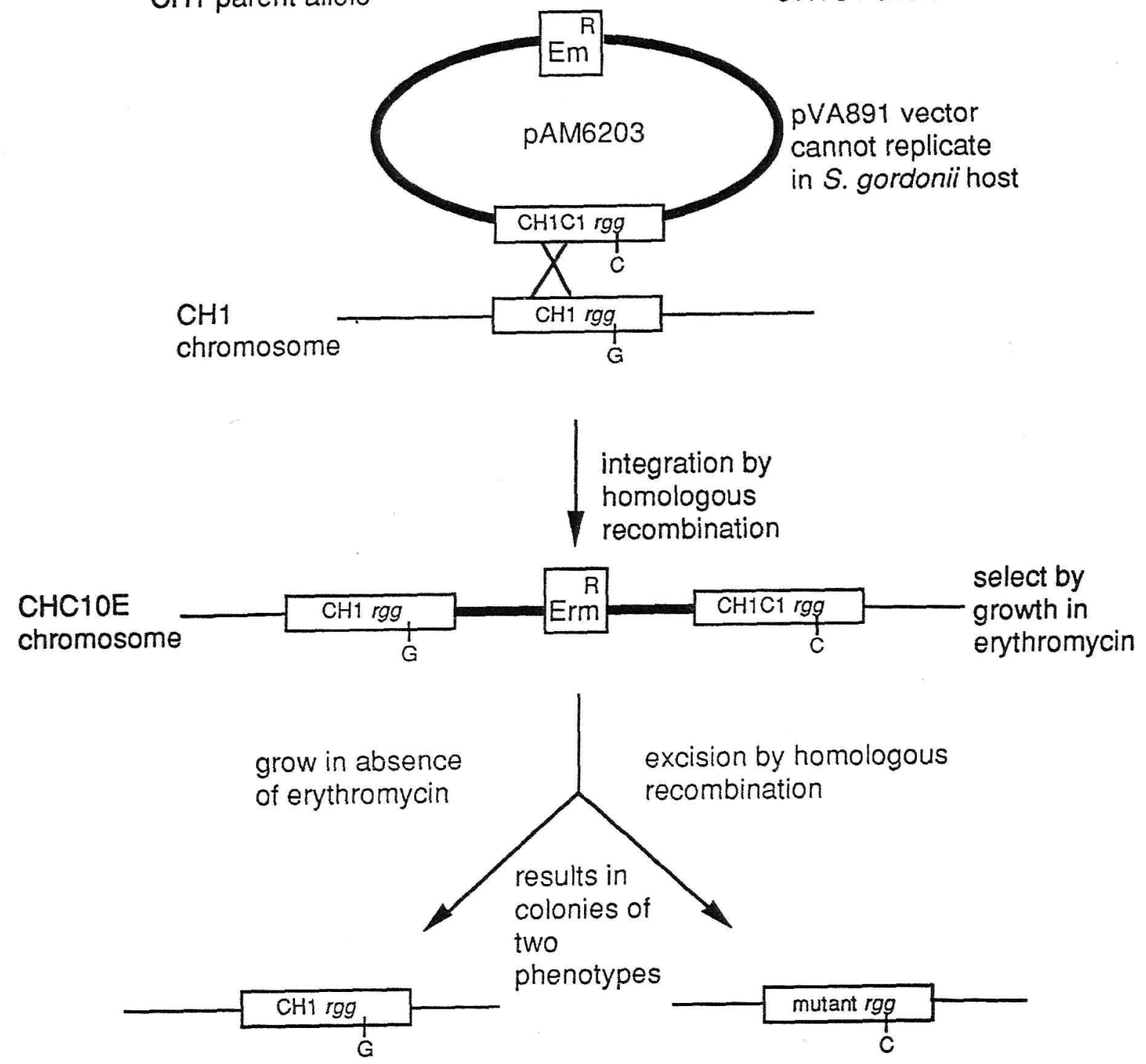

relevant phenotypes:

$$
\begin{array}{ll}
\text { erythromycin sensitive } & \text { erythromycin sensitive } \\
\mathrm{Spp}^{+} \text {on sucrose agar } & \mathrm{Spp}^{-} \text {on sucrose agar }
\end{array}
$$

Fig. 3. Diagram of the construction of strains $\mathrm{CHC} 102$ and $\mathrm{CHC} 105$, the $\mathrm{Spp}^{-}$, erythromycinsensitive strains that contains the point mutation found in the rgg gene of strain $\mathrm{CH} 1 \mathrm{Cl}$, and strain $\mathrm{CHC10H}$, the $\mathrm{Spp}^{+}$erythromycin-sensitive strain with the parental rgg sequence.

been buffer-equilibrated or coated with human saliva. Supernatants containing unattached bacteria were removed; the beads containing attached bacteria were washed and counted in a scintillation counter. Radiolabel counts were correlated with bacterial numbers, and adhesion was expressed as the number of attached bacteria per $10 \mathrm{mg}$ of beads. Statistical comparisons between strains were done by a one-tailed Student $t$ test.

\section{Hemolysin production}

$\beta$-hemolysin production by bacterial strains was detected on agar medium containing $4 \%$ washed horse blood in $1 \%$ LabLemco, $1 \%$ peptone, $0.5 \% \mathrm{NaCl}$ (Oxoid, Unipath, Nepean, Ontario), $\mathrm{pH}$ 7.3 , as previously described (11). Plates were incubated anaerobically and strain
$\mathrm{CH} 1$, which does not produce $\beta$-hemolysin, and strain $\mathrm{CH} 1 \mathrm{Cl}$, which is $\beta$ hemolytic under these conditions, were used as negative and positive controls, respectively.

\section{Results \\ Spp ${ }^{-}$strains produce less extracellular glucosyltransferase antibody-reactive protein than Spp ${ }^{+}$strains}

Western blot analyses showed that a basis for the decreased glucosyltransferase activity in $\mathrm{Spp}^{-}$phase variant strains was their decreased amount of extracellular glucosyltransferase protein. The Spp ${ }^{+}$strains (Fig. 2, lanes 1, 3 and 5) had approximately 3- to 5-fold more glucosyltransferase antibody-reactive protein than the $\mathrm{Spp}^{-}$strains (Fig. 2, lanes 2, 4 and 6), and the relative intensities of the antibody-reactive protein bands correlated to the intensities of glucan bands on activity gels for these strains (28).

\section{Comparison of glucan products of Spp ${ }^{+}$ and Spp strains}

${ }^{13} \mathrm{C}-\mathrm{NMR}$ spectra of glucans produced by partially purified glucosyltransferases from the parental $\mathrm{Spp}^{+}$strain $\mathrm{CH} 1$ and the $\mathrm{Spp}^{-}$strain $\mathrm{CH} 97$ were similar (data not shown) to previously published ${ }^{13} \mathrm{C}$-NMR spectra of glucans produced by strain Challis (10). The peak positions and ratios of areas under the peaks representing the carbons in the $\mathrm{C} 1, \mathrm{C} 3$ and $\mathrm{C} 6$ positions of the glucose moieties in the glucans were similar in spectra from both strains, indicating that the glucans made by glucosyltransferase enzymes from strain $\mathrm{CH} 1$ and $\mathrm{CH} 97$ were similar. Thus, the glucans produced in vitro by strains CH1 and CH97 appear to differ primarily in quantity rather than quality.

Comparison of nucleotide sequences of rgg and gtfG regions of Spp phase variants

To examine glucosyltransferase phase variation at the DNA level, the nucleotide sequences of a series of sequentially derived phase variant strains (CH1A8, CH1B1, CH1C1 and CH1D2) and the independently derived $\mathrm{Spp}^{-}$ strain $\mathrm{CH} 97$ were examined. Since preliminary evidence suggested that glucosyltransferase phase variation can occur in more than one way (33), regions with the seemingly greatest potential for controlling gtfG expression were examined in all five phase variant strains (Fig. 1). These regions included: the upstream regions and dyad symmetry regions at the beginning of $r g g$ and $g t f G$, which could affect nucleic acid secondary structure and could act as potential binding sites for regulatory factors; the rgg regulatory determinant for $g t f G$ expression; the signal sequence of $g t f G$, which encodes the region responsible for transport of the functional enzyme; the putative active site region; the carboxyl terminal repeats involved in glucan binding; and the gtfG stop codon and downstream region of dyad symmetry. In addition, the entire gtfG gene and its flanking regions were examined in strain $\mathrm{CH} 97$, which has the highest reversible frequency for glucosyltransferase phase variation $\left(10^{-3}\right.$ in both directions) (28). 


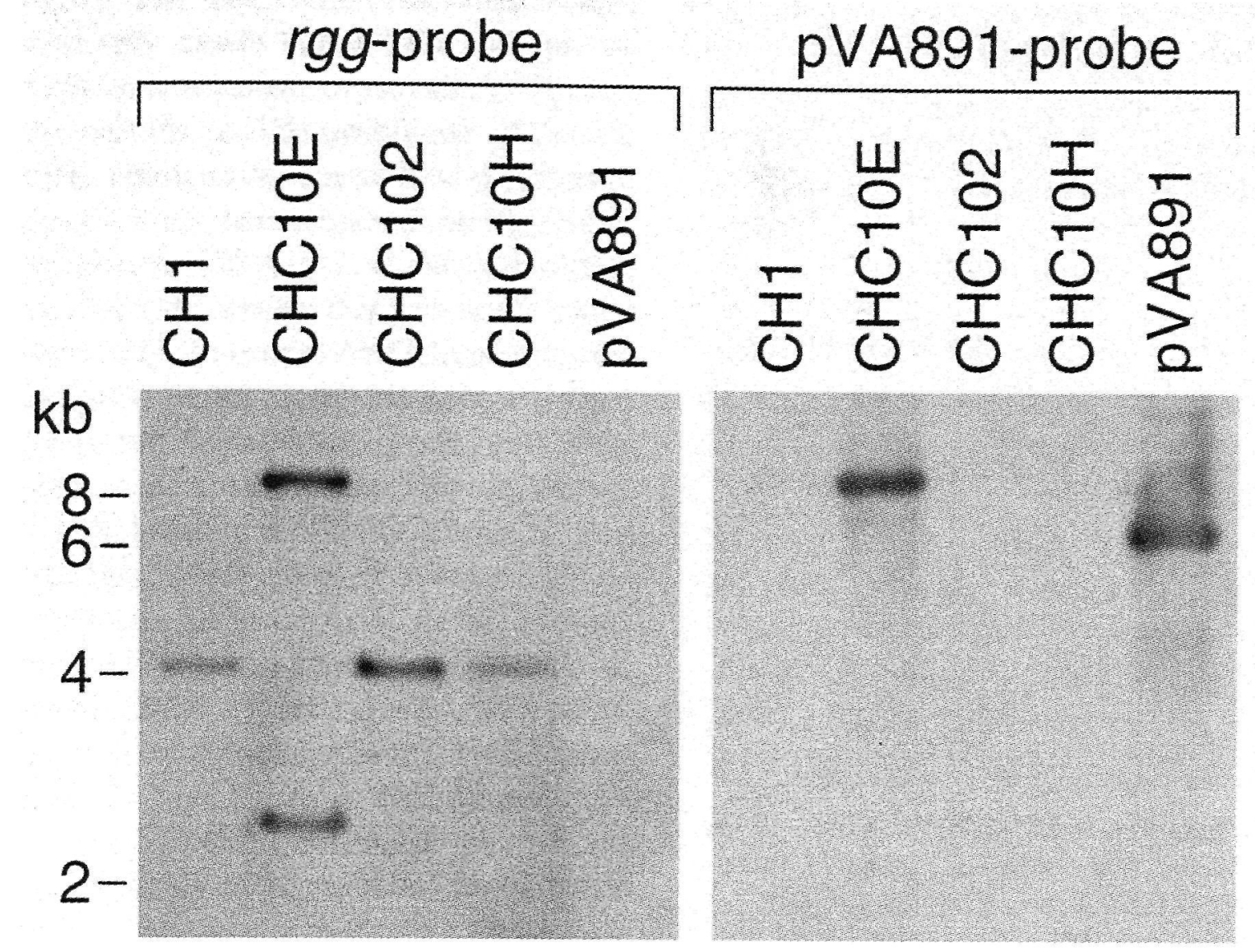

Fig. 4. Southern hybridization analysis of HindIII-digested chromosomal DNA from strains $\mathrm{CH} 1, \mathrm{CHC10E}, \mathrm{CHC} 102$ and $\mathrm{CHC10H}$ probed with an internal fragment of rgg (34) (left panel) and pVA891 (right panel). DNA size standards (Bethesda Research Laboratories) ran as marked.

No differences from the parental sequence were found in the regions of nucleotide sequences of $g t f G$ examined in any of the phase variant strains; nor were any differences seen in the regions flanking $r g g$ and $g t f G$, indicating that changes in these regions are not responsible for phase variation in these strains. The nucleotide sequence of the rgg structural gene was also the same as the strain $\mathrm{CH} 1$ parent sequence in strains $\mathrm{CH} 1 \mathrm{~A} 8, \mathrm{CH} 1 \mathrm{~B} 1, \mathrm{CH} 1 \mathrm{D} 2$ and $\mathrm{CH} 97$ indicating that differences in the known $g t f G$ regulatory determinant, $r g g$, were not responsible for variable expression of $g t f G$ in these strains. However, strain $\mathrm{CH} 1 \mathrm{C1}$, an $\mathrm{Spp}^{-}$variant of strain $\mathrm{CH} 1 \mathrm{~B} 1$, had a point mutation in the $\mathrm{rgg}$ structural gene.

\section{Construction and characterization of strains with the rgg of strain $\mathrm{CH} 1 \mathrm{C} 1$}

In the rgg of strain $\mathrm{CH} 1 \mathrm{C} 1$ a guanine was replaced by a cytosine, resulting in a change at amino acid number 271 (27) from an aspartate (negative charge) to a histidine (positive charge) residue. To see whether this point mutation was related to the $\mathrm{Spp}^{-}$colony morphology, the mutation was introduced into the $\mathrm{Spp}^{+}$parental strain $\mathrm{CH} 1$ by homologous recombination in a strategy previstrain $\mathrm{CH} 1$ and transformants were selected on erythromycin agar. Since pVA891 does not have a gram-positive origin of replication, only those colonies with pAM6203 integrated into the chromosome would be expected to grow under these conditions. The erythromycin-resistant transformants theoretically carried both a $\mathrm{CH} 1$ parental rgg gene and a $\mathrm{CH} 1 \mathrm{C} 1$ mutated rgg gene (Fig. 3).

An erythromycin-resistant transformant colony was chosen and designated CHC10E. The insertion of pAM6203 into the rgg gene of strain $\mathrm{CHC} 10 \mathrm{E}$ was confirmed by Southern hybridization analysis (Fig. 4) using probes for $r g g$ (34) and pVA891. This strain was then grown in the absence of erythromycin so that the integrated vector could be lost by recombination of the flanking homologous DNA, theoretically resulting in both strains with the parental $r g g$
Table 2. Adhesion to hydroxyapatite and saliva-coated hydroxyapatite beads

\begin{tabular}{lcc}
\hline Strain & \multicolumn{2}{c}{ Substratum } \\
& hydroxyapatite & $\begin{array}{c}\text { saliva-coated } \\
\text { hydroxyapatite }\end{array}$ \\
\hline $\mathrm{CH} 1$ & $7.68 \pm 0.85$ & $4.92 \pm 0.50$ \\
$\mathrm{CH} 1 \mathrm{C} 1$ & $17.34 \pm 0.53$ & $15.73 \pm 0.15$ \\
$\mathrm{CHC} 102$ & $8.17 \pm 0.40$ & $5.27 \pm 0.07$ \\
$\mathrm{CHC} 105$ & $8.12 \pm 0.56$ & $5.10 \pm 0.50$ \\
\hline
\end{tabular}

Number of washed, radiolabelled bacteria $\times 10^{6}( \pm \mathrm{SD})$ attached to hydroxyapatite and saliva-coated hydroxyapatite beads after 3.5 hours incubation. Tests were done in duplicate and repeated twice. The percentage recovery of total radioactive counts ([number of counts in the supernatant plus number of counts on the beads divided by the initial washed cell counts $/ \mathrm{ml}] \times 100$ ) for all tests ranged from $85 \%$ to $98 \%$.

and strains with the $\mathrm{CH} 1 \mathrm{C} 1 \mathrm{rgg}$. As expected, after selection for erythromycin sensitivity, both $\mathrm{Spp}^{+}$and $\mathrm{Spp}^{-}$strains were recovered. An $\mathrm{Spp}^{-}$colony designated $\mathrm{CHC102}$ and an $\mathrm{Spp}^{+}$colony $\mathrm{CHC} 10 \mathrm{H}$ were chosen for further analysis. Southern hybridization analysis of these strains (Fig. 4) indicated that each contained only one copy of $r g g$ and did not contain the integrated pVA891 plasmid. Nucleotide sequence analysis confirmed that the rgg gene of strain CHC102 was identical to that of strain $\mathrm{CH} 1 \mathrm{C1}$. An additional erythromycin sensitive, $\mathrm{Spp}^{-}$strain $\mathrm{CHC} 105$ also had the $\mathrm{CH} 1 \mathrm{Cl}$ rgg sequence. Furthermore, nucleotide sequence analysis of strain $\mathrm{CHC10H}$, an erythromycin sensitive, $\mathrm{Spp}^{+}$derivative of strain $\mathrm{CHC10E}$ had the parental rgg sequence.

\section{The $\mathrm{CH} 1 \mathrm{C} 1 \mathrm{rgg}$ allele is related to} decreased glucosyltransferase activity

Glucosyltransferase activity gels showed that strain $\mathrm{CHC102}$ had glucosyltransferase activity levels similar to that of strain $\mathrm{CH} 1 \mathrm{C} 1$ (Fig. 5). Western blot analyses (Fig. 2, lane 7) indicated that like strain $\mathrm{CH} 1 \mathrm{C} 1$, strain $\mathrm{CHC} 102$ had low levels of extracellular glucosyltransferase protein. These results imply that the point mutation in the rgg determinant of strain $\mathrm{CH} 1 \mathrm{C} 1$ was related to the $\mathrm{Spp}^{-}$colony morphology and low level of extracellular glucosyltransferase protein. However, since the $\mathrm{Spp}^{-}$strains $\mathrm{CH} 1 \mathrm{~A} 8$ and $\mathrm{CH} 97$ had the parental $\mathrm{rgg}$ sequence, a change in rgg was not the basis for decreased glucosyltransferase activity in all $\mathrm{Spp}^{-}$strains. 


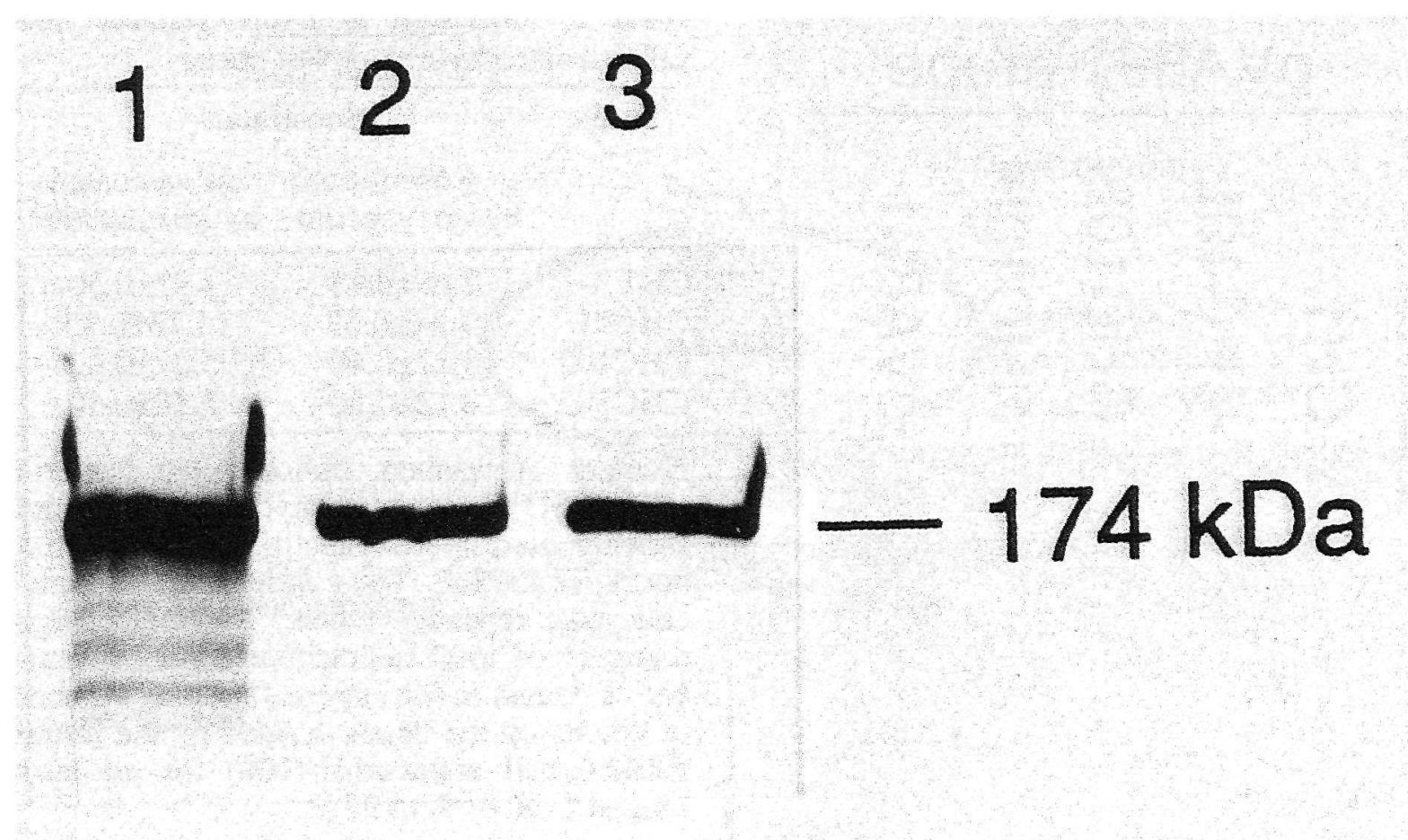

Fig. 5. Glucosyltransferase activity gel of the same preparations used for Western blots in Fig. 2 shows the level of glucosyltransferase activity of the parental strain $\mathrm{CH} 1$ (lane 1), the decreased level of activity of the $\mathrm{Spp}^{-}$phase variant strain $\mathrm{CH} 1 \mathrm{Cl}$ (lane 2) and the similarly low activity of strain $\mathrm{CHC102}$ (lane 3), the derivative of strain $\mathrm{CHC10E}$ with the same point mutation in rgg as strain $\mathrm{CH} 1 \mathrm{C} 1$. Strain $\mathrm{CHC10H}$, the strain $\mathrm{CHC1OE}$ derivative with the parental rgg sequence, had a glucosyltransferase activity level similar to that of strain $\mathrm{CH} 1$ (data not shown).

Although strains $\mathrm{CHC102}$ and CHC105 had the rgg point mutation and $\mathrm{Spp}^{-}$colony type of strain $\mathrm{CH} 1 \mathrm{C} 1$, they differed from strain $\mathrm{CH} 1 \mathrm{C} 1$ in two previously described phase variable phenotypes $(11,32)$. Strain $\mathrm{CH} 1 \mathrm{C} 1$ has shown increased adhesion to saliva-coated hydroxyapatite compared with the $\mathrm{Spp}^{+}$ strains $\mathrm{CH} 1, \mathrm{CH} 1 \mathrm{~B} 1$ and CH1D2 (32). Strain $\mathrm{CH} 1 \mathrm{C} 1$ also produces a $\beta$-hemolysin that is not produced by the parental strain (11). However, whereas $\mathrm{CH} 1 \mathrm{C} 1$ showed increased attachment to both hydroxyapatite or saliva-coated hydroxyapatite beads $(P<0.002$ and $P<0.001$, respectively; Table 2 ), neither strain $\mathrm{CHC102}$ nor CHC105 attached to either substratum significantly more than the parent (Table 2). Furthermore, neither $\mathrm{CHC102}$ nor CHC105 produced $\beta$-hemolysin on washed blood agar plates. Thus, the nucleotide change in $\mathrm{rgg}$, which caused decreased glucosyltransferase activity, was not responsible for these additional phenotypic changes in strain $\mathrm{CH} 1 \mathrm{Cl}$.

\section{Discussion}

The glucosyltransferase of $S$. gordonii is unique in several ways. In addition to being the only glucosyltransferase with an identified regulatory determinant, $r g g$ (27), it is, to our knowledge, the only oral streptococcal glucosyltransferase reported to undergo a phase variation phenomenon. It was previously shown that the spontaneous $\mathrm{Spp}^{-}$phase variant strains have less glucosyltransferase activity than the $\mathrm{Spp}^{+}$strains (28); the Western blot analysis presented here indicates that this decreased activity is a quantitative difference due to decreased amounts of extracellular glucosyltransferase protein in the $\mathrm{Spp}^{-}$strains. The mobility of active glucosyltransferase proteins on SDS $6 \%$ polyacrylamide gels stained for glucosyltransferase activity (28; unpublished results) and the location of glucosyltransferase antibody-reactive proteins in immunoblots suggested that the five phase variant strains examined in this study had glucosyltransferase enzymes of the same molecular weight. These results did not preclude changes in enzyme size that were too small to be noted by gel electrophoresis. However, nucleotide sequence analysis of the region encoding the glucosyltransferase amino terminus as well as the region encoding the carboxyl terminus and downstream region in five phase variant strains confirmed that the size of the $g t f G$ open reading frame in these strains was identical. Indeed, all the regions of $g t f G$ examined in these strains were identical.

The mechanisms underlying the decreased amounts of extracellular glucosyltransferase protein and activity ap- pear to differ among the Spp- strains examined in this study. Phase variation events are known to occur in a number of ways, including DNA inversions, frameshifts and/or recombinations (19). Although no changes had been found previously in the $\mathrm{rgg} / \mathrm{gtfG}$ region of phase variants by Southern analysis of chromosomal DNA digested with various restriction enzymes (27), it was possible that changes occurred but were simply not detected. Indeed, examination of strain $\mathrm{CH} 1 \mathrm{C} 1$ indicated that a point mutation in the $g t f G$ regulatory gene, rgg, had occurred. This point mutation in rgg was not present in either strain $\mathrm{CH} 1 \mathrm{~A} 8$ or $\mathrm{CH} 1 \mathrm{~B} 1$ from which strain $\mathrm{CH} 1 \mathrm{C} 1$ was sequentially derived. Furthermore, it was not present in strain $\mathrm{CH} 1 \mathrm{D} 2$, the $\mathrm{Spp}^{+}$strain reported to be a revertant of $\mathrm{CH} 1 \mathrm{Cl}$ (28). Although the probability of the exact nucleotide reversion occurring in strain CH1D2 would seem extremely low, this region of $r g g$ may be a hot spot for mutations and/or our selection conditions of plating on sucrose agar picked up this rare mutation. Alternatively, there may have been an error in determining the lineage when these strains were originally isolated (28). However, the identical biochemical profiles and DNA restriction patterns (unpublished data) of strains $\mathrm{CH} 1 \mathrm{~B} 1, \mathrm{CH} 1 \mathrm{C} 1$ and $\mathrm{CH} 1 \mathrm{D} 2$ and the parental strain $\mathrm{CH} 1$ confirm that $\mathrm{CH} 1 \mathrm{C} 1$ is an $\mathrm{Spp}^{-}$derivative, and $\mathrm{CH} 1 \mathrm{~B} 1$ and $\mathrm{CH} 1 \mathrm{D} 2$ are $\mathrm{Spp}^{+}$derivatives of the parental strain $\mathrm{CH} 1$. Examination of strain $\mathrm{CHC102}$, which contained an $\mathrm{rgg}$ allele with the same point mutation found in the rgg of $\mathrm{CH} 1 \mathrm{C} 1$, suggested that this point mutation conferred an $\mathrm{Spp}^{-}$colony morphology and decreased the level of extracellular glucosyltransferase; these results confirm the importance of rgg in glucosyltransferase regulation. However, the point mutation in rgg did not confer the changes in adhesive and hemolytic phenotypes that occur in strain $\mathrm{CH} 1 \mathrm{Cl}$ (11) to any of the strain $\mathrm{CHC} 10 \mathrm{E}$ derivatives examined. This finding supported previous studies (11) that suggested that phase variation in multiple phenotypes of $S$. gordonii is not related solely to $r g g$ and probably involves more than one mechanism.

The basis of glucosyltransferase phase variation in strains $\mathrm{CH} 1 \mathrm{~A} 8$, CH1B1, CH1D2 and CH97 is still undetermined. Nucleotide sequence analysis 
of $\mathrm{rgg}$ and $g t f G$ subclones from $\mathrm{Spp}^{+}$ and $\mathrm{Spp}^{-}$strains showed no changes in regions known to be involved in enzyme function. The possibility of nucleotide changes in regions of $g t f G$ that were not sequenced in strains $\mathrm{CH} 1 \mathrm{~A} 8$, CH1B1 and CH1D2 cannot be ruled out. Specific amino acid changes in $S$. mutans glucosyltransferases have been shown to influence the type of glucan produced (25). However, the ${ }^{13} \mathrm{C}$-nuclear magnetic resonance data indicated that the glucans produced in vitro by the parental strain $\mathrm{CH} 1$ and the $\mathrm{Spp}^{-}$strain CH97 were similar. Although nuclear magnetic resonance cannot accurately quantify the proportion of glucose moieties in each linkage within a glucan, since the samples were run under identical conditions, the similar peak positions and ratios of the areas under each peak can be compared (24). The data suggest that, at least for strain $\mathrm{CH} 97$, phase variation appears to affect primarily the quantity rather than the quality of the glucosyltransferase. Nucleotide sequence analysis confirmed that the entire $r g g / g t f G$ and flanking regions in strain $\mathrm{CH} 97$ were identical to those of the parental strain. However, these in vitro results do not preclude the possibility that, in vivo, other factors could influence both the level of glucosyltransferase expressed and glucan products made by $\mathrm{Spp}^{+}$and $\mathrm{Spp}^{-}$strains. These could include post-translational modifications of the enzyme and/or factors that affect the level of glucosyltransferase translocated across the cell membrane, as has been postulated to occur in Streptococcus salivarius (7). Furthermore, other, as yet undescribed, DNA region(s) may be responsible for the differential expression of $g t f G$ and a basis for glucosyltransferase phase variation. Indeed, two distinct, unlinked genetic loci have been reported to increase glucosyltransferase activity in $S$. gordonii Challis (10). Both rgg and gtfG are preceded by regions of dyad symmetry that have been previously hypothesized to function in regulation of gene expression (27). Distally located genes might encode trans-acting factors that act at the $r g g$ and/or $g t f G$ loci.

The present studies indicate that phase variation involves primarily quantitative rather than qualitative changes in glucosyltransferase, which can occur without nucleotide changes in the structural gene, $g t f G$ or its known regulatory gene, $r g g$. These results provide an essential basis for future studies aimed at understanding the complex genetic and environmental interactions that regulate $S$. gordonii glucosyltransferase.

\section{Acknowledgments}

This work was supported by Public Health Service grants DE10217 and DE11090 to M. M. V. from the National Institutes of Health. We thank H. K. Kuramitsu for providing anti-GTF-I antiserum, S. Woehler for performing the nuclear magnetic resonance spectroscopy and N. M. Gardner and J. D. Nowak for providing technical assistance.

\section{References}

1. Appelbaum B, Golub E, Holt S, Rosan B. In vitro studies of dental plaque formation: adsorption of oral streptococci to hydroxyapatite. Infect Immun 1979: 25: 717-728.

2. Ausubel FM, Brent B, Kingston RE et al. Current protocols in molecular biology. New York: John Wiley \& Sons, 1987.

3. Colson P, Jennings HJ, Smith ICP. Composition, sequence and conformation of polymers and oligomers of glucose as revealed by carbon-13 nuclear magnetic resonance. J Am Chem Soc 1974: 96: 8081-8087.

4. Ferretti JJ, Gilpin ML, Russell RRB. Nucleotide sequence of a glucosyltransferase gene from Streptococcus sobrinus MFe28. J Bacteriol 1987: 169: 42714278.

5. Frandsen EVG, Pedrazzoli V, Kilian M. Ecology of viridans streptococci in the oral cavity and pharynx. Oral Microbiol Immunol 1991: 6: 129-133.

6. Funane K, Shiraiwa M, Hashimoto K, Ichishima E, Kobayashi M. An activesite peptide containing the second essential carboxyl group of dextransucrase from Leuconostoc mesenteroides by chemical modifications. Biochemistry 1993: 32: 13696-13702.

7. Giffard PM, Simpson CL, Milward CP, Jacques NA. Molecular characterization of a cluster of at least two glucosyltransferase genes in Streptococcus salivarius ATCC 25975. J Gen Microbiol 1991: 137: 2577-2593.

8. Grahame DA, Mayer RM. Purification and comparison of two forms of dextransucrase from Streptococcus sanguis. Carbohydr Res 1985: 142: 285-298.

9. Gribskov M, Burgess RR. Sigma factors from E. coli, B. subtilis, phage SP01 and phage $\mathrm{T} 4$ are homologous proteins. Nucleic Acids Res 1986: 14: 6745-6763.
10. Haisman RJ, Jenkinson HF. Mutants of Streptococcus gordonii Challis overproducing glucosyltransferase. J Gen Microbiol 1991: 137: 483-489.

11. Jones GW, Clewell DB, Charles LG, Vickerman MM. Multiple phase variation in haemolytic, adhesive and antigenic properties of Streptococcus gordonii. Microbiology 1996: 142: 181-189.

12. Laemmli UK. Cleavage of structural proteins during the assembly of the head of bacteriophage T4. Nature 1970: 227 : 690-685.

13. Lawson J, Gooder H. Growth and development of competence in the group $\mathrm{H}$ streptococci. J Bacteriol 1970: 102: 820-825.

14. Loesche WJ. Role of Streptococcus mutans in human dental decay. Microbiol Rev 1986: 50: 353-380.

15. Macrina FL, Evans RP, Tobian JA, Hartley DL, Clewell DB, Jones KR. Novel shuttle plasmid vehicles for Escherichia-Streptococcus transgeneric cloning. Gene 1983: 25: 145-150.

16. Mooser $\mathrm{G}$, Wong $\mathrm{C}$. Isolation of a glucan binding domain of glucosyltransferase (1,6 alpha glucan synthase) from Streptococcus sobrinus. Infect Immun 1988: 56: 880-884.

17. Mooser G, Hefta SA, Paxton RJ, Shively JE, Lee TD. Isolation and sequence of an active site peptide containing a catalytic aspartic acid from two Streptococcus sobrinus $\alpha$-glucosyltransferases. J Biol Chem 1991: 266: 89168922.

18. Parker MT, Ball LC. Streptococci and aerococci associated with systemic infection in man. J Med Microbiol 1976: 9: 275-302.

19. Plasterk RHA. Genetic switches: mechanism and function. Trends in Genetics 1992: 8: 403-406.

20. Robertson BD, Meyer TF. Genetic variation in pathogenic bacteria. Trends Genet 1992: 8: 422-427.

21. Sanger F, Nicklen S, Couson AR. DNA sequencing with chain-terminating inhibitors. Proc Natl Acad Sci U S A 1977: 74: 5463-5467.

22. Scheld WM, Valone JA, Sande MA. Bacterial adherence in the pathogenesis of endocarditis. J Clin Invest 1978: 61: 1394-1404.

23. Seymour FR, Knapp RD, Lambers BL. Unusual dextrans. Structural analysis of soluble D-glucans from strains of Streptococcus mutans by C-13-nuclear magnetic resonance spectroscopy. Carbohydr Res 1980: 84: 187-195.

24. Shimamura A. Use of ${ }^{13} \mathrm{C}-\mathrm{NMR}$ spectroscopy for the quantitative estimation of ${ }^{3-} \mathrm{O}$ - and 3,6-di- $O$-substituted D-glucopyranosyl residues in $\alpha$-D-glucans formed by the D-glucosyltransferases of Streptococcus sobrinus. Carbohydr Res 1989: 185: 239-248.

25. Shimamura A, Nakano Y, Mukasa $H$, Kuramitsu HK. Identification of amino 
acid residues in Streptococcus mutans glucosyltransferases influencing the structure of the glucan product. J Bacteriol 1994: 176: 4835-4850.

26. Shiroza T, Ueda S, Kuramitsu HK. Sequence analysis of the gtfB gene from Streptococcus mutans. J Bacteriol 1987: 169: 4263-4270.

27. Sulavik MC, Tardif G, Clewell DB. Identification of a gene, $r g g$, which regulates expression of glucosyltransferase and influences the Spp phenotype of Streptococcus gordonii Challis. J Bacteriol 1992: 174: 3577-3586.

28. Tardif G, Sulavik MC, Jones GW, Clewell DB. Spontaneous switching of the sucrose-promoted colony phenotype in Streptococcus sanguis. Infect Immun 1989: 57: 3945-3948

29. Terleckyj B, Willett NP, Shockman GD. Growth of several cariogenic strains of oral streptococci in a chemically defined medium. Infect Immun 1975: 11: 649 655.

30. Vickerman MM, Clewell DB, Jones GW. Sucrose-promoted accumulation of growing glucosyltransferase variants of Streptococcus gordonii on hydroxyapatite surfaces. Infect Immun 1991: 59: 3523-3530.

31. Vickerman MM, Clewell DB, Jones GW. Ecological implications of glucosyltransferase phase variation in Streptococcus gordonii. Appl Environ Microbiol 1991: 57: 3648-3651.

32. Vickerman MM, Clewell DB, Jones GW. Glucosyltransferase phase variation in Streptococcus gordonii modifies adhesion to saliva-coated hydroxyapatite surfaces in a sucrose-independent manner. Oral Microbiol Immunol 1992. 7: 118-120.
33. Vickerman MM, Sulavik MC, Clewell DB. Molecular analysis of Streptococcus gordonii glucosyltransferase phase variants. In: Ferretti JJ, Gilmore MS, Klaenhammer TR, Brown F, ed. Genetics of streptococci, enterococci and lactococci. Development of Biological Standards. Basel: Karger, 1995: 85: 309-314.

34. Vickerman MM, Sulavik MC, Clewell DB. Oral streptococci with genetic determinants similar to the glucosyltransferase regulatory gene, rgg. Infect Immun 1995: 63: 4524-4527.

35. Vickerman MM, Sulavik MC, Nowak JD, Gardner NM, Jones GW, Clewell DB. Nucleotide sequence analysis of the Streptococcus gordonii glucosyltransferase gene, gtfG. DNA Sequence (in press). 
This document is a scanned copy of a printed document. No warranty is given about the accuracy of the copy. Users should refer to the original published version of the material. 